\section{Evolving concepts in the primary prevention of cardiovascular disease: aspirin then and now}
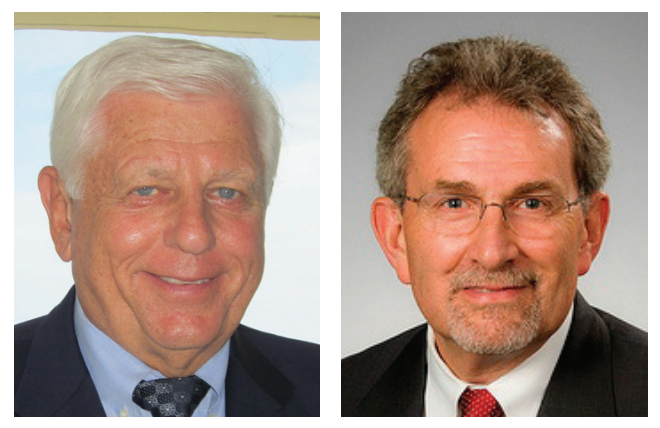

\author{
“...aspirin, which was termed \\ the wonder drug of the 20th \\ century, may become the \\ wonder drug of the \\ 21st century.”
}

Charles H Hennekens*,1 \& David J Bjorkman²

Hippocrates, the Greek physician of the Age of Pericles, who is generally considered to be the father of western medicine, found that an extract from the bark of white willow trees relieved aches and pains. Later, it was discovered that the bark contains salicin, a closely related compound of aspirin. In 1897, Felix Hoffman, a chemist working at Bayer in Elberfeld, Germany, synthesized the first stable form of aspirin. He was motivated, in part, to help his father, who suffered from painful and disabling arthritis. In the 20th century, aspirin became the most widely used drug in the world. It was not until 1971 that Sir John Vane elucidated the novel mechanism of aspirin irreversibly inhibiting platelet aggregation, for which he received the Nobel Prize for Physiology in Medicine in 1982 [1].

At that time, observational studies and several trials of secondary prevention suggested benefits of aspirin on recurrent myocardial infarction (MI), but the data were inconclusive for stroke and deaths from cardiovascular disease (CVD). Later, large-scale randomized evidence of the benefits of aspirin on MI, stroke and CVD deaths emerged from a wide range of survivors of prior occlusive events, as well as from those suffering from acute MI or occlusive stroke. As the absolute benefits were far higher than the absolute risks, predominantly gastrointestinal (GI) upset and major extracranial bleeding, aspirin has come to be widely prescribed for all high-risk patients.

In primary prevention, the Physician's Health Study (PHS), funded as an investigator-initiated research grant by the NIH, randomized 22,071 dedicated and conscientious male physicians at low risk of a first CVD event. On 18 December 1987, the independent Data and Safety Monitoring Board unanimously recommended early termination of the aspirin component, principally due to the emergence of a statistically extreme $(\mathrm{p}<0.00001)$ reduction in risk of a first MI. On 25 January 1988,

'Charles E Schmidt College of Medicine, Florida Atlantic University, 777 Glades Road, Building 71, Suites 210 \& 337, Boca Raton, FL 33431, USA

*Author for correspondence: Tel.: +1 561297 4474; chenneke@fau.edu

Future
Medicine
part of 
“...aspirin significantly decreased the risk of a first myocardial infarction, but increased major extracranial bleeds and the main risk factors for cardiovascular disease were also risk factors for bleeding." the preliminary results were reported [2] and the final results showed that aspirin produced a $44 \%$ reduction in risk of a first MI ( $<<0.00001)$ [3]. Since then, additional trials and meta-analyses [4] have been published, mostly among low-risk men and women. There is now proof beyond a reasonable doubt that aspirin reduces risks of a first MI, but the data on stroke and CVD death remain inconclusive $[4,5]$.

In a comprehensive meta-analysis of six major primary prevention trials, aspirin significantly decreased the risk of a first MI, but increased major extracranial bleeds and the main risk factors for CVD were also risk factors for bleeding. In the secondary prevention trials, aspirin produced highly statistically significant absolute reductions in serious vascular events (6.7 vs $8.2 \%$ per year; $\mathrm{p}<0.0001$ ), coronary events ( 4.3 vs $5.3 \%$ per year; $\mathrm{p}<0.0001$ ) and total stroke ( 2.08 vs $2.54 \%$ per year; $\mathrm{p}=0.002$ ). In the primary and secondary prevention trials, aspirin produced similar proportional reductions in serious vascular events in men and women $[4,5]$.

With regards to dose, indirect comparisons of benefits from meta-analyses showed no differences between 75 and over $1500 \mathrm{mg}$ daily. By contrast, higher doses produced greater risks of major extracranial bleeds, but this trend was statistically significant only above $325 \mathrm{mg}$ daily. In secondary prevention patients, the proportional increases in risk of major extracranial bleeds were similar with all daily doses of aspirin $<325 \mathrm{mg}$ (odds ratio [OR]: 1.7, 95\% CI: 0.8-3.3 for $<75 \mathrm{mg}$; OR: 1.5 , 95\% CI: $1.0-2.3$ for 75-150 mg; and OR: 1.4, 95\% CI: $1.0-2.0$ for $160-325 \mathrm{mg}$ ) [1]. Two trials that directly compared $75-325 \mathrm{mg}$ aspirin with $<75 \mathrm{mg}$ daily showed no significant differences in major extracranial bleeds [6]. Finally, the UK-TIA trial randomized 2435 patients to either $300 \mathrm{mg}$ $(\mathrm{n}=816)$ or $1200 \mathrm{mg}(\mathrm{n}=806)$ daily aspirin or placebo $(n=814)$ [7]. The rates of GI upset were $25 \%$ in the placebo group, $29 \%$ in the $300 \mathrm{mg}$ group and $39 \%$ in the $1200 \mathrm{mg}$ group, and the rates for major bleeds were 1.6, 2.6 and 4.9\%, respectively. For patients at high risk of occlusive vascular events, these absolute risks of GI upset and major bleeding are small in relation to the absolute benefits of aspirin. In primary prevention, however, the existing totality of evidence is incomplete. The primary prevention trials were well designed, conducted and analyzed, but only $9 \%$ of approximately 100,000 subjects had 10-year risks of coronary heart disease (CHD) $>10 \%$, so these subgroup data are not, on their own, reliable [5].

Thus, it was essential to identify apparently healthy subjects with the potential to derive net benefits from aspirin, specifically those with multiple risk factors for CHD. Such primary prevention subjects are at intermediate cardiovascular risk between that observed in the completed trials of primary $(<10 \%)$ and secondary prevention $(>20 \%)$. Four large-scale randomized trials of intermediate-risk primary prevention subjects are ongoing and might yield the necessary more reliable evidence [8]. ARRIVE is a randomized, double-blind, placebo-controlled trial that has enrolled over 12,000 men and women with a 10 -year risk of CHD of $>15 \%$ using a modification of the Framingham Risk Score. ASPREE is enrolling elderly individuals aged $\geq 70$ years. ASCEND and ACCEPT-D define intermediate risk as the presence diabetes mellitus. Achieving high levels of adherence and follow-up in these trials is necessary in order to provide reliable evidence regarding the absolute benefits and risks of aspirin for primary prevention subjects at intermediate cardiovascular risk.

Until the results of these trials are available, judgments regarding prescribing aspirin for primary prevention should continue to be made on an individual basis by the healthcare provider. In addition, at present, general guidelines advocating the routine use of aspirin in apparently healthy individuals are premature. Finally, the increasing global burden of CVD in both developed and developing countries underscores the need for the more widespread use of drugs of proven net benefit, such as statins to lower cholesterol and various drugs, usually in combination, to lower blood pressure $[5,8]$. With respect to the use of aspirin in primary prevention, the healthcare provider must weigh any absolute benefits against any absolute risks in deciding whether to prescribe the drug. Aspirin increases serious upper GI complications by twofold [9] and also increases lower GI bleeding [10]. Risk factors for aspirin-associated GI bleeding have been identified [11] and the risk can be mitigated by prophylactic gastric acid reduction therapy [12].

In summary, in secondary prevention, among a very wide range of survivors of prior occlusive CVD events, as well as those suffering acute MI or occlusive stroke, aspirin decreases subsequent 
risks of MI, stroke and CVD death. In high-risk patients, the absolute benefits are large and clear and the absolute risks are small in comparison, so aspirin should be more widely prescribed. By contrast, in primary prevention, the data from randomized trials primarily conducted among low-risk subjects show that aspirin reduces the risks of a first MI, but the evidence for stroke and CVD death remain inconclusive. Based on the current totality of the evidence, decisions to prescribe aspirin for primary prevention should be individual clinical judgments by the healthcare provider that weigh the absolute benefit in terms of reducing the risk of a first MI against the absolute risk of major bleeding. If the ongoing trials of intermediate-risk subjects show net benefits, then general guidelines may be justified, but with several caveats. First, any decision to use aspirin in secondary or primary prevention should continue to be made by the healthcare provider. Second, therapeutic lifestyle changes and other drugs of life-saving benefit, such as statins, should be considered with aspirin as an adjunct, not an alternative. The more widespread and appropriate use of aspirin in the primary prevention of CVD is particularly attractive, especially in developing countries, where CVD is emerging as the leading cause of death. In addition, aspirin is generally widely available because it is sold over the counter and, more importantly, the drug is extremely inexpensive [13].

Several other discoveries, some very recent, include novel mechanisms as well as findings from observational epidemiologic studies and randomized trials of other potential benefits of aspirin in other diseases. In recent findings from randomized trials in high-risk primary prevention subjects [14] and among patients with chronic stable coronary disease [15], all clinically relevant doses of aspirin significantly

\section{References}

1 Hennekens $\mathrm{CH}$, Schneider WR. The need for wider and appropriate utilization of statins and aspirin in treatment and prevention of cardiovascular disease. Exp. Rev. Cardiovasc. Ther. 6(1), 95-107 (2008).

2 Findings from the aspirin component of the ongoing Physicians' Health Study. N. Engl. J. Med. 318, 262-264 (1988).

3 Final report on the aspirin component of the ongoing Physicians' Health Study. Steering Committee of the Physicians' Health Study increased nitric oxide formation. These observations have contributed to the formulation of the hypothesis that aspirin inhibits the progression of atherosclerosis. Of greater and more immediate clinical benefit are observational epidemiologic studies, as well as randomized trials, indicating that the benefits of aspirin and statins are at least additive [16]. Observational studies and randomized trials also suggest the potential of aspirin for the prevention and treatment of migraine [17], for delaying the progression of memory loss [18] and for the prevention of a variety of cancers, especially colorectal cancer [19]. For these and other cogent reasons, aspirin, which was termed the wonder drug of the 20th century, may become the wonder drug of the 21 st century.

\section{Financial \& competing interests disclosure}

$\mathrm{CH}$ Hennekens serves as an independent scientist in an advisory role to: investigators and sponsors as Chair or Member of Data and Safety Monitoring Boards for Amgen, AstraZeneca, Bayer, Bristol Myers-Squibb, British Heart Foundation, Cadila, Canadian Institutes of Health Research, Genzyme, Lilly, Sanofi, Sunovion and the Wellcome Foundation; to Pfizer, the US FDA and $U_{p} T o D a t e ;$ receives royalties for authorship or editorship of three textbooks and as a coinventor on patients for inflammatory markers and cardiovascular disease that are held by Brigham and Women's Hospital; and has an investment management relationship with the West-Bacon Group within SunTrust Investment Services, which has discretionary investment authority and does not own any common or preferred stock in any pharmaceutical or medical device company. The authors have no other relevant affliations or financial involvement with any organization or entity with a financial interest in or financial conflict with the subject matter or materials discussed in the manuscript apart from those disclosed.

No writing assistance was utilized in the production of this manuscript.
Research Group. N. Engl. J. Med. 321, 129-135 (1989).

4 Antithrombotic Trialists (ATT) Collaboration; Baigent C, Blackwell $\mathrm{L}$, Buring $\mathrm{J}$ et al. Aspirin in the primary and secondary prevention of vascular disease: collaborative meta-analysis of individual participant data from randomized trials. Lancet 373, 1849-1860 (2009).

5 Hennekens $\mathrm{CH}$, Bjorkman DJ. The risks and benefits of prophylactic aspirin in vascular disease and cancer: what is a doctor to do? Clin. Invest. 3(5), 447-449 (2013).
6 Hennekens $\mathrm{CH}$, Sechenova O, Hollar D, Serebruany V. Dose of aspirin in the treatment and prevention of cardiovascular disease; current and future directions. J. Cardiovasc. Pharm. Ther. 11(3), 1-7 (2006).

7 United Kingdom Trial of Transient Ischaemic Attacks (UK-TIA) aspirin trial: interim results. UK-TIA Study Group. Br. Med. J. (Clin. Res. Ed.) 296, 316-320 (1988).

8 Hennekens $\mathrm{CH}$, Baigent C. Aspirin in primary prevention: good news and bad news. Nat. Rev. Cardiol. 9, 262-263 (2012). 
9 Garcia-Rodriguez LA, Hernandez-Diaz S, de Abajo FJ. Association between aspirin and upper gastrointestinal complications: systematic review of epidemiologic studies. Br. J. Clin. Pharmacol. 52, 563-571 (2001).

10 Cryer B, Mahaffey KW. Gastrointestinal ulcers, role of aspirin and clinical outcomes; pathobiology diagnosis and treatment. J. Multidiscip. Health 7, 137-146 (2014).

11 Weil J, Colin-Jones D, Langman M et al. Prophylactic aspirin and risk of peptic ulcer bleeding. BMJ 310, 827-830 (1995).

12 Yeomans N, Lanas A, Labenz J et al. Efficacy of esomeprazole (20 mg once daily) for reducing the risk of gastroduodenal ulcers associated with continuous use of low-dose aspirin. Am. J. Gastroenterol. 103, 2465-2473 (2008).
13 Hennekens $\mathrm{CH}$, DeMets D. Aspirin in primary prevention of cardiovascular disease: the need for individual clinical judgments based on absolute benefits and risks. Nat. Rev. Cardiol. doi:10.1038/nrcardio.2014.88 (2014) (Epub ahead of print).

14 Hennekens $\mathrm{CH}$, Schneider WR, Pokov A et al. A randomized trial of aspirin at clinically relevant doses and nitric oxide formation in humans. J. Cardiovasc. Pharmacol. Ther. 15, 344-348 (2010).

15 Hetzel S, De Mets D, Schneider R et al. Aspirin increases nitric oxide formation in chronic stable coronary disease. J. Cardiovasc. Pharmacol. Ther. 18(3), 217-221 (2013).

16 Hennekens CH, Sacks F, Tonkin A et al. Additive benefits of pravastatin and aspirin to decrease risks of cardiovascular disease: randomized and observational comparisons of secondary prevention trials and their meta-analysis. Arch. Int. Med. 164, 40-44 (2004)

17 Buring JE, Peto R, Hennekens CH. Low-dose aspirin for migraine prophylaxis: findings from a randomized trial of U.S. physicians. JAMA 264, 1711-1713 (1990).

18 Sturmer T, Glynn RJ, Field TS, Taylor JO, Hennekens $\mathrm{CH}$. Aspirin use and cognitive function in the elderly. Am. J. Epidemiol. 143, 683-691 (1996).

19 Elwood PC, Mustafa M, Almonte M, Morgan G. The risks and benefits of prophylactic aspirin in vascular disease and cancer. Clin. Invest. 2, 1177-1184 (2012). 